\title{
NUMERICAL ANALYSIS OF THE THERMAL DAMAGE PROCESS OF THE TISSUE-BLOOD VESSEL SYSTEM AND DISTRIBUTION OF OXYGEN IN THE TISSUE
}

\author{
MAREK JASIŃSKI \\ Silesian University of Technology, Department of Computational Mechanics and Engineering, Gliwice, Poland \\ e-mail: marek.jasinski@polsl.pl
}

\begin{abstract}
The paper presents a numerical analysis of the thermal damage process taking place in biological tissue containing a blood vessel during laser irradiation. The internal heat source resulting from laser irradiation based on the solution of the optical diffusion equation is taken into account. The investigation was concerned with the influence of tissue denaturation and oxygen content in blood on temperature distribution. The analysis of oxygen transport to the tissue is treated as a part of the analysis of thermal damage processes. At the stage of numerical computations, the boundary element method and the finite difference method were used.
\end{abstract}

Keywords: bioheat transfer, oxygen transport, Arrhenius integral, laser-tissue interactions

\section{Introduction}

Blood and its components play many important roles in a living organism, i.e. they transport oxygen and nutrients to cells and, on the way back, carbon dioxide, a waste product of metabolism. Blood circulation is also responsible for maintaining normal body temperature (normothermia) and water-electrolyte balance (homeostasis).

Blood consists of cellular components (approximately 45\%) and plasma (approximately 55\%). The former consist mainly of red blood cells (RBC or erythrocytes), white blood cells (WBC or leukocytes) and platelets (thrombocytes). The most numerous components are red blood cells which contain haemoglobin responsible for binding and transporting oxygen (Bessonov et al., 2016; Caro et al., 2012).

From the point of view of optical properties of blood, the concentration of haemoglobin in RBC makes it the most absorbing element of blood in the wavelength range of $250-1100 \mathrm{~nm}$. Due to the difference in the refractive index between red blood cells and the surrounding blood plasma, red blood cells also prevail over blood scattering. Oxygen saturation affects the optical properties of the blood as well: oxygenated blood has a lighter and more vivid red shade than deoxygenated blood. Other components that can affect the optical properties of blood are various proteins, nutritious compounds, or pharmaceuticals (Bosschaart et al., 2014; Friebel et al., 2006).

Laser irradiation of tissue causes different reactions, i.e. thermal interactions which can lead to permanent tissue damage. It is obvious that in the presence of blood vessels in the tissue, heating and damage processes take place slightly differently from those of homogeneous tissue. Because of motion of the blood, which has a cooling effect, the energy contained in the heat impulse does not migrate deep into the tissue and is drained by blood circulation. The aforementioned oxygen saturation of the blood can also have an impact on these processes (Bosschaart et al., 2014; Friebel et al., 2006).

Mathematical description of the processes taking place during laser irradiation of biological tissue containing blood vessels can be divided into stages related to modelling of laser energy 
deposition, blood velocity determination, temperature distribution and thermal damage modelling. It is also possible to use an additional model for the analysis of oxygen transport to the tissue.

It can be said that the main part of this type of analysis is related to temperature distribution which can be determined by making use of the bioheat transfer equation. It should be pointed out that the equation describing temperature distribution in the domain of the blood vessel usually has an additional component related to blood velocities, the so-called advection term (Gonzalez-Suarez and Berjano, 2016; Hassanpour and Saboonchi, 2016; Paul and Paul, 2018).

The earliest of bioheat transfer equations, but probably still the most widely used, is the Pennes equation (Abraham and Sparrow, 2007; Paruch, 2017). The newest equations, such as GDPL equation (generalized dual-phase lag equation), take into account a heterogeneous structure of biological tissue (Dombrovski, 2012; Majchrzak et al., 2019).

To solve the bioheat transfer equation, one must know the light distribution. For this purpose, radiative transport equation is usually taken into account, which can be solved by the statistical Monte Carlo approach or one of several modifications in the discrete ordinates method (Dombrovski, 2012; Friebel et al., 2006; Jacques and Pogue, 2008). It is also possible to approximate the light transport using the optical diffusion equation (Korczak and Jasiński, 2019; Majchrzak et al., 2019).

The next step in the analysis of laser-tissue interaction is the estimation of the degree of tissue thermal damage. For this purpose, the so-called Arrhenius injury integral is usually applied (Abraham and Sparrow, 2007; Akula and Maniyeri, 2020; Paruch, 2020). It assumes that tissue damage is irreversible, even in the case of a temporary, small, local increase of temperature. There are also models that make it possible to take into account withdrawal of the tissue injury in such cases, e.g., the TTIW algorithm (Jasiński, 2018).

Models of oxygen distribution are often based on the Krogh cylinder concept (McGuire and Secomb, 2001; Zhu et al., 2015). These models have been developed and, at present, they allow one to take into account a number of phenomena such as intravascular resistance to oxygen diffusion or the influence of other substances (e.g. myoglobin or haemoglobin) (Whiteley et al., 2002).

This work aims at analysing the process of thermal damage in the 2D non-homogeneous domain, consisting of soft tissue and a blood vessel, subjected to a laser impulse.

The novelty aspect of the paper is primarily the incorporation of an oxygen distribution model into the analysis of thermal damage processes. It was realized by a combination of two models at different scales (tissue-blood vessel model and Krogh cylinder). Additionally, different values of optical parameters for tissue and blood resulting from the saturation level and tissue damage were taken into account. The light distribution in both subdomains was determined on the basis of the optical diffusion equation. Thermal analysis is based on the Pennes equation for the tissue subdomain, while for the blood vessel subdomain the advection-diffusion equation is used. Using this model, the degrees of thermal damage for different values of optical parameters of tissue and blood were also calculated. At the stage of numerical realization, different methods were used.

\section{Governing equations}

The analysis was carried out on the basis of two models presented in Fig. 1. On the left-hand side of this figure, the domain under consideration in the thermal damage problem subjected to laser action is presented. It consists of two subdomains: tissue $\Omega_{t}$ and blood vessel $\Omega_{v}$ (Jasiński, 2020a). The second model is related to the delivery of oxygen to biological tissue. As this phenomenon occurs at the capillary level, the model is based on the Krogh cylinder concept (McGuire and 
Secomb, 2001; Whiteley et al., 2002; Zhu et al., 2015). Similarly to the thermal damage problem model, two subdomains can be distinguished in this model: tissue $\Omega_{K t}$ and capillary $\Omega_{K c}$. Since dimensions of the Krogh cylinder are much smaller than dimensions of the thermal damage model (micrometers vs. millimeters), the oxygen distribution model corresponds to the selected point in the domain of tissue $\Omega_{t}$ in the thermal damage model.
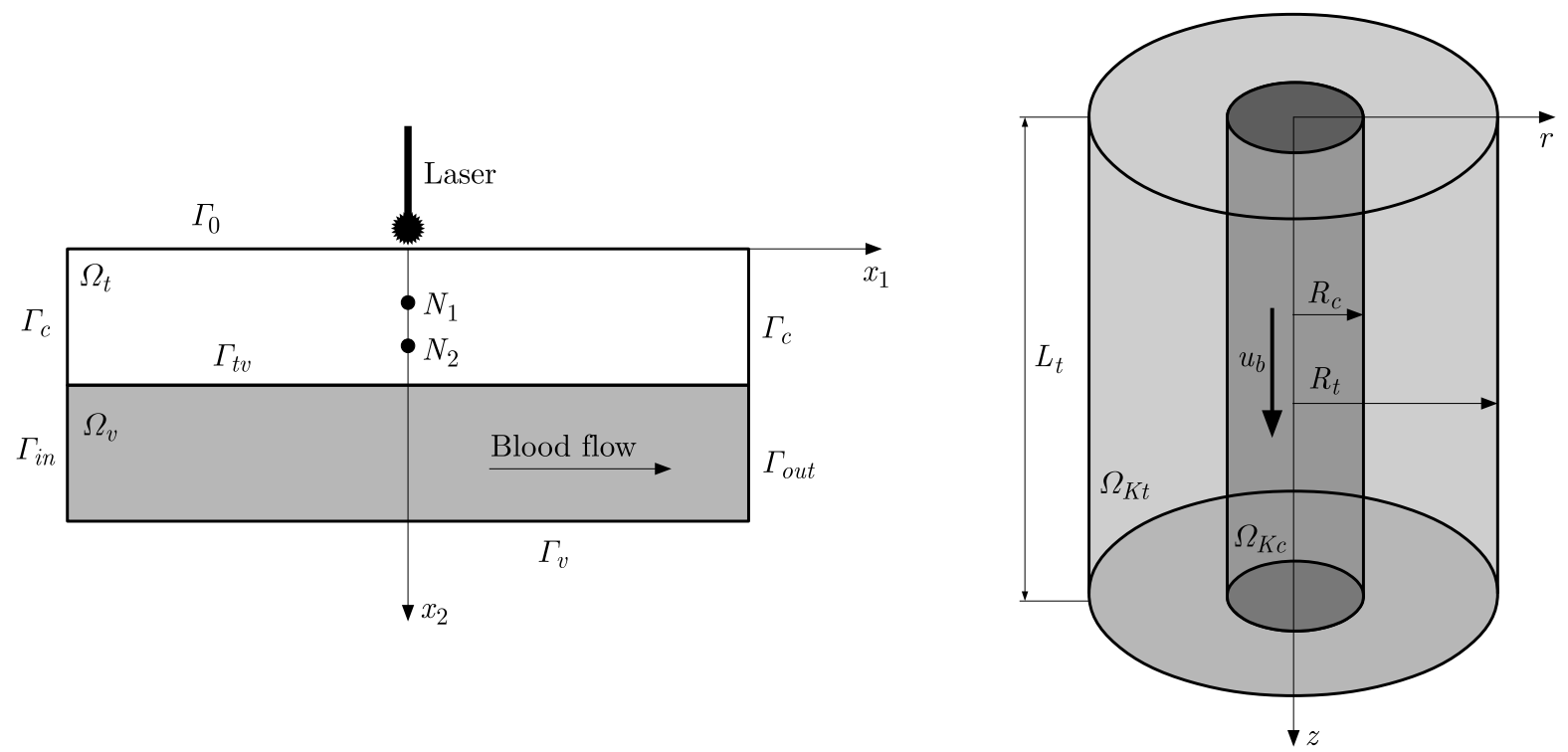

Fig. 1. The domains considered in the thermal damage problem (left) and oxygen distribution problem (right)

The oxygen distribution model is associated with the thermal damage model through the perfusion coefficient $w\left[\mathrm{~m}_{\text {blood }}^{3} \mathrm{~m}_{\text {tissue }}^{-3} \mathrm{~s}^{-1}\right]$ and the blood velocity in the capillary $u_{b}\left[\mathrm{~cm} \mathrm{~s}^{-1}\right]$. The first of these parameters, the perfusion coefficient is a characteristic feature of any soft tissue, related to the total volume of blood in the tissue. It is obvious that its value is influenced by the volumes and velocities of blood in all blood vessels contained in the soft tissue domain. So the relationship between the perfusion coefficient and the blood velocity in the capillary can be denoted as (McGuire and Secomb, 2001)

$$
w=\frac{Q_{b}}{\pi R_{t}^{2} L_{t}}=\frac{\pi R_{c}^{2} u_{b}}{\pi R_{t}^{2} L_{t}} \quad \rightarrow \quad u_{b}=w L_{t} \frac{R_{t}^{2}}{R_{c}^{2}}
$$

where $Q_{b}\left[\mathrm{~cm}^{3} \mathrm{~s}^{-1}\right]$ is the blood flow rate in the capillary while $R_{c}, R_{t}$, and $L_{t}$ are geometrical parameters of the oxygen distribution model (see Fig. 1).

It should be pointed out that the perfusion coefficient is often treated as a marker of tissue damage, so in this paper it is assumed to be damage-dependent in form (Abraham and Sparrow, 2007)

$$
w=w(A r r)= \begin{cases}\left(1+25 A r r-260 A r r^{2}\right) w_{0} & 0 \leqslant A r r \leqslant 0.1 \\ (1-A r r) w_{0} & 0.1<A r r \leqslant 1 \\ 0 & A r r>1\end{cases}
$$

where $w_{0}$ is the initial perfusion coefficient while Arr denotes the Arrhenius injury integral (Majchrzak et al., 2019; Paruch, 2020)

$$
\operatorname{Arr}\left(x_{1}, x_{2}, t^{F}\right)=\int_{0}^{t^{F}} A \exp \left[-\frac{E}{R T\left(x_{1}, x_{2}, t\right)}\right] d t
$$


where $R\left[\mathrm{~J}\right.$ mole $\left.{ }^{-1} \mathrm{~K}^{-1}\right]$ is the universal gas constant, $E\left[\mathrm{~J} \mathrm{~mole}^{-1}\right]$ is the activation energy, $A\left[\mathrm{~s}^{-1}\right]$ is the preexponential factor.

There are two values treated as necrosis criteria: $\operatorname{Arr}\left(x_{1}, x_{2}\right)=1$ and $\operatorname{Arr}\left(x_{1}, x_{2}\right)=4.6$ which correspond to $63 \%$ and $99 \%$ of cell death at a specific point $\left(x_{1}, x_{2}\right)$, respectively. Furthermore, in this work, the TTIW algorithm (thermal tissue injury withdrawal algorithm) has been applied to model the possibility of tissue injury withdrawal when the thermal impulse is stopped (Jasiński, 2018).

In order to determine the degree of thermal damage of the tissue, the temperature field in the domain considered must be known (Fig. 1 left). Transient heat transfer in the subdomains of the thermal damage model is described by the Pennes bioheat transfer equation (tissue subdomain) (Korczak and Jasiński, 2019; Paruch, 2017) and the advection-diffusion equation (blood vessel subdomain) (Gonzalez-Suarez and Berjano, 2016; Hassanpour and Saboonchi, 2016; Paul and Paul, 2018), which form

$$
\begin{array}{ll}
\left(x_{1}, x_{2}\right) \in \Omega_{t}: \quad c_{t} \rho_{t} \frac{\partial T_{t}\left(x_{1}, x_{2}, t\right)}{\partial t}=\lambda_{t} \nabla^{2} T_{t}\left(x_{1}, x_{2}, t\right)+Q_{\text {perf }}\left(x_{1}, x_{2}, t\right) \\
\\
+Q_{\text {last }}\left(x_{1}, x_{2}, t\right)+Q_{\text {met }} \\
\left(x_{1}, x_{2}\right) \in \Omega_{v}: \quad c_{v} \rho_{v} \mathbf{u} \nabla T_{v}\left(x_{1}, x_{2}, t\right)=\lambda_{v} \nabla^{2} T_{v}\left(x_{1}, x_{2}, t\right)+Q_{\text {las } v}\left(x_{1}, x_{2}, t\right)+Q_{\text {met } v}
\end{array}
$$

where (subscripts $t$ and $v$ refer to the subdomains of tissue and blood vessel, respectively) $\lambda\left[\mathrm{Wm}^{-1} \mathrm{~K}^{-1}\right]$ is the thermal conductivity, $c\left[\mathrm{Jkg}^{-1} \mathrm{~K}^{-1}\right]$ is the specific heat, $\rho\left[\mathrm{kg} \mathrm{m}^{-3}\right]$ is the density, $T$ is the temperature, while $\mathbf{u}=[u, v]\left[\mathrm{m} \mathrm{s}^{-1}\right]$ is the velocity vector. The components $Q_{\text {perf }}$, $Q_{\text {las }}$, and $Q_{\text {met }}\left[\mathrm{W} \mathrm{m}^{-3}\right]$ are the internal heat sources associated with perfusion, metabolism and laser irradiation. In the current work, the metabolic heat source $Q_{m e t}$ is assumed to be a constant value.

The perfusion heat source function $Q_{\text {perf }}$ is described by the formula (Paruch, 2017, 2020)

$$
Q_{\text {perf }}\left(x_{1}, x_{2}, t\right)=c_{b} \rho_{b} w\left[T_{b}-T_{t}\left(x_{1}, x_{2}, t\right)\right]
$$

where $c_{b}\left[\mathrm{Jkg}^{-1} \mathrm{~K}^{-1}\right]$ is the specific heat of blood, $\rho_{b}\left[\mathrm{~kg} \mathrm{~m}^{-3}\right]$ is the density and $T_{b}$ corresponds to the arterial blood temperature.

Equations (2.4) are supplemented by convection boundary conditions on the boundaries $\Gamma_{0}$ and $\Gamma_{t v}$, while on the remaining boundaries no-flux conditions are assumed.

The blood velocity field is calculated using the Navier-Stokes equation which consists of a momentum equation and a mass equation with adequate boundary conditions for the inlet, outlet and wall of the blood vessel (Gonzalez-Suarez and Berjano, 2016; Müller et al., 2013)

$$
\begin{aligned}
\left(x_{1}, x_{2}\right) \in \Omega_{v}: \quad & \rho_{v} \mathbf{u} \cdot \nabla \mathbf{u}=-\nabla p\left(x_{1}, x_{2}\right)+\mu \nabla^{2} \mathbf{u}+F \\
& \nabla \cdot \mathbf{u}=0
\end{aligned}
$$

where $p[\mathrm{~Pa}]$ denotes pressure, $\mu[\mathrm{Pas}]$ is the dynamic viscosity, $F\left[\mathrm{~N} \mathrm{~m}^{-3}\right]$ denotes volume forces (not considered in this analysis).

It should be pointed out that blood is generally a non-Newtonian fluid, but in the case of assumption that length and time scales are sufficiently large in comparison to length and time scales at the level of an individual erythrocyte it could be treated as a Newtonian fluid modelled by making use of the Navier-Stokes equation (Bessonov et al., 2016; Gonzalez-Suarez and Berjano, 2016; Haghighi et al., 2015).

The internal heat source associated with laser energy deposition $Q_{\text {las }}$ has the form (Korczak and Jasiński, 2019; Majchrzak et al., 2019)

$$
Q_{\text {las }}\left(x_{1}, x_{2}, t\right)=\mu_{a} \phi\left(x_{1}, x_{2}\right) \quad \phi\left(x_{1}, x_{2}\right)=\phi_{c}\left(x_{1}, x_{2}\right)+\phi_{d}\left(x_{1}, x_{2}\right)
$$


where $\phi, \phi_{c}, \phi_{d}\left[\mathrm{~W} \mathrm{~m}^{-2}\right]$ denote the total light fluence rate, the collimated and diffuse parts of the fluence rate, respectively, while $\mu_{a}\left[\mathrm{~m}^{-1}\right]$ is the absorption coefficient.

The collimated fluence rate is given as the Beer-Lambert law in the form (Majchrzak et al., 2019)

$$
\phi_{c}\left(x_{1}, x_{2}\right)=\phi_{0} \exp \left(-\frac{2 x_{1}^{2}}{r^{2}}\right) \exp \left(-\mu_{t}^{\prime} x_{2}\right)
$$

while in order to determine the diffuse fluence rate, the steady-state optical diffusion equation must be solved (Dombrovsky, 2012; Majchrzak et al., 2019)

$$
\left(x_{1}, x_{2}\right) \in \Omega_{t} \cup \Omega_{v}: \quad \nabla\left[\frac{1}{3 \mu_{t}^{\prime}} \nabla \phi_{d}\left(x_{1}, x_{2}\right)\right]-\mu_{a} \phi_{d}\left(x_{1}, x_{2}\right)+\mu_{s}^{\prime} \phi_{c}\left(x_{1}, x_{2}\right)=0
$$

where $\phi_{0}\left[\mathrm{~W} \mathrm{~m}^{-2}\right]$ is the surface irradiance of laser, $r$ is radius of the laser beam, $\mu_{t}^{\prime}\left[\mathrm{m}^{-1}\right]$ is the attenuation coefficient and $\mu_{s}^{\prime}\left[\mathrm{m}^{-1}\right]$ is the effective scattering coefficient.

All the details of the thermal damage problem which are not mentioned in this paper can be found in (Jasiński, 2020).

The oxygen distribution problem is described by two separate equations for radial and axial directions (Fig. 1 right). In the radial direction, for the tissue subdomain, the following equation is assumed (McGuire and Secomb, 2001; Jasiński 2020)

$$
\begin{array}{ll}
R_{c}<r<R_{t}: \quad K_{t} \frac{1}{r} \frac{d}{d r}\left[r \frac{d P_{t}(r)}{d r}\right]=M_{t}\left(P_{t}\right) & M_{t}\left(P_{t}\right)=\frac{M_{0} P_{t}(r)}{P_{0}+P_{t}(r)} \\
r=R_{c}: & 2 \pi R_{c} K_{t} \frac{d P_{t}(r)}{d r}=-k\left[P_{b}-P_{t}(r)\right] \\
r=R_{t}: & \frac{d P_{t}(r)}{d r}=0
\end{array}
$$

where $P_{t} \quad[\mathrm{mmHg}]$ is the partial pressure of oxygen in the tissue, $K_{t}$ $\left[\left(\mathrm{cm}^{2} \mathrm{~s}^{-1}\right)\left(\mathrm{cm}_{\mathrm{O} 2}^{3} \mathrm{~cm}^{-3}(\mathrm{mmHg})^{-1}\right)\right]$ is the Krogh diffusion coefficient while $M_{t}\left(P_{t}\right)$ represents the oxygen consumption rate. In the current work, it is assumed in the form of Michaelis-Menten kinetics, where $M_{0}\left[\mathrm{~cm}_{\mathrm{O} 2}^{3} \mathrm{~cm}^{-3} \mathrm{~s}^{-1}\right]$ is the oxygen demand and $P_{0}[\mathrm{mmHg}]$ is the half-maximum oxygen consumption. In the boundary conditions: $k\left[\left(\mathrm{~cm}^{2} \mathrm{~s}^{-1}\right)\left(\mathrm{cm}_{\mathrm{O} 2}^{3} \mathrm{~cm}^{-3}(\mathrm{mmHg})^{-1}\right)\right]$ is the mass transfer coefficient, $P_{b}[\mathrm{mmHg}]$ is the partial pressure of oxygen in the blood (i.e. in the capillary subdomain), while the right-hand side of the condition for $r=R_{c}$ represents the intravascular resistance to oxygen diffusion at the blood-tissue interface (McGuire and Secomb, 2001).

With the blood flow along the capillary, oxygen is released from haemoglobin and diffused to tissue, so the partial oxygen pressure in the blood decreases. It can be expressed in the form of an equation for the axial direction

$$
Q_{b} \kappa_{b} \frac{d\left[S_{H b}\left(P_{b}\right)\right]}{d z}=-k\left(P_{b}-\left.P_{t}\right|_{r=R_{c}}\right) \quad S_{H b}\left(P_{b}\right)=\frac{P_{b}^{n}}{P_{b}^{n}+P_{50}^{n}}
$$

where $z$ is the axial coordinate, $\kappa_{b}\left[\mathrm{~cm}_{O 2}^{3} \mathrm{~cm}_{\text {blood }}^{-3}\right]$ is the oxygen carrying capacity of blood, $S_{H b}$ is the oxyhaemoglobin saturation, and the relationship between $S_{H b}$ and $P_{b}$ is given by the Hill equation where $P_{50}[\mathrm{mmHg}]$ is the half-maximum haemoglobin saturation and $n$ is the Hill coefficient (McGuire and Secomb, 2001; Whiteley, 2002; Zhu et al., 2015).

\section{Methods of solution}

In this paper, two models presented in Fig. 1 are considered. They are related to thermal damage to soft tissue in the vicinity of a blood vessel (Fig. 1 left) and a model related to oxygen distribution (Fig. 1 right). The transient temperature field in the thermal damage problem is described 
by equation (2.4), while the thermal damage is determined from the Arrhenius integral (2.3). Note that both formulas defined for the tissue subdomain $\Omega_{t}$ and the blood vessel subdomain $\Omega_{v}$ contain source components related to $Q_{\text {las }}$ laser effects. Their value was determined based on formulas (2.7)-(2.9). Among them, steady-state optical diffusion equation (2.9) is particularly important. Since the model assumes constant optical parameters for $\Omega_{t}$ and $\Omega_{v}$ domains, the process of solving (2.9) could be performed separately, and then the obtained values of the diffuse fleuence rate $\phi_{d}$ were imported as a data file into the thermal damage model.

In the model, it was also assumed that the velocity field $\mathbf{u}$ calculated on the basis of Navier-Stockes equation (2.6) is constant during the entire process of heating and cooling of the tissue-blood vessel system. Therefore, this analysis was separated into a separate task, realized in Comsol Multiphysics for a stationary fluid flow, and its results were also imported into the thermal damage model via a data file.

In the thermal damage model, the temperature (Eq. (2.4)), the degree of thermal damage (Eq. (2.3)) and the damage-dependent perfusion coefficient value (Eq. (2.2)) were determined. For the latter, for a selected point from the tissue subdomain $\Omega_{t}$ (Fig. 1 left) and for selected time steps, the value of blood velocity in the capillary $u_{b}$ was determined according to formula (2.1). This parameter was necessary for the steady-state analysis of the oxygen distribution described by equations (2.10)-(2.11) and for the model shown in Fig. 1 right.

The main part of the problem considered was the determination of temperature (2.4) and degree of thermal damage (2.3) in the tissue and blood vessel system discussed, as shown in Fig. 1 left.

To solve the 2D bioheat transfer problem, the 1st scheme of the boundary element method (tissue subdomain $\Omega_{t}$ ) was used, whereas the advection-diffusion equation (blood vessel subdomain $\Omega_{v}$ ) was solved using the finite difference method. Weak coupling was used, which means that during calculations between these two subdomains temperature values at the boundary $\Gamma_{t v}$ were transmitted.

For the transient heat diffusion problem, for a time grid with a constant step $\Delta t$, the boundary integral equation corresponding to transition $t^{f-1} \rightarrow t^{f}$ is of the form (Brebia and Dominguez, 1992)

$$
\begin{aligned}
& B(\xi) T\left(x_{1}, x_{2}, t^{f}\right)+\frac{1}{c} \int_{t^{f-1}}^{t^{f}} \int_{\Gamma} T^{*}\left(\xi, x_{1}, x_{2}, t^{f}, t\right) q\left(x_{1}, x_{2}, t\right) d \Gamma d t \\
& =\frac{1}{c} \int_{t^{f-1}}^{t^{f}} \int_{\Gamma} q^{*}\left(\xi, x_{1}, x_{2}, t^{f}, t\right) T\left(x_{1}, x_{2}, t\right) d \Gamma d t \\
& +\iint_{\Omega} T^{*}\left(\xi, x_{1}, x_{2}, t^{f}, t^{f-1}\right) T\left(x_{1}, x_{2}, t^{f-1}\right) d \Omega \\
& +\frac{1}{c} \int_{t^{f-1}}^{t^{f}} \iint_{\Omega} Q_{v}\left(x_{1}, x_{2}, t\right) T^{*}\left(\xi, x_{1}, x_{2}, t^{f}, t\right) d \Omega d t
\end{aligned}
$$

In equation (3.1), $T^{*}$ and $q^{*}$ are the fundamental solution and the heat flux resulting from the fundamental solution (Brebia and Dominguez, 1992) while $B(\xi)$ is a coefficient from the interval $(0,1)$. In this paper, constant boundary elements have been used. Details concerning numerical realization of the BEM can be found, among others, in (Jasiński, 2018, 2020).

As was already mentioned for solving the advection-diffusion equation, the finite difference method has been used. A uniform grid based on five-point stencils was introduced (Majchrzak 
et al., 2019). The differential quotients approximating the derivatives which have been used are in the form

$$
\begin{aligned}
& {\left[\nabla T\left(x_{1}, x_{2}, t\right)\right]_{i, j}=\left[\frac{\partial T\left(x_{1}, x_{2}, t\right)}{\partial x_{1}}+\frac{\partial T\left(x_{1}, x_{2}, t\right)}{\partial x_{2}}\right]_{i, j}=\frac{T_{i+1, j}-T_{i-1, j}}{2 h}+\frac{T_{i, j+1}-T_{i, j-1}}{2 h}} \\
& {\left[\nabla^{2} T\left(x_{1}, x_{2}, t\right)\right]_{i, j}=\left[\frac{\partial^{2} T\left(x_{1}, x_{2}, t\right)}{\partial x_{1}^{2}}+\frac{\partial^{2} T\left(x_{1}, x_{2}, t\right)}{\partial x_{2}^{2}}\right]_{i, j}} \\
& \quad=\frac{T_{i+1, j}-2 T_{i, j}+T_{i-1, j}}{h^{2}}+\frac{T_{i, j+1}-2 T_{i, j}+T_{i, j-1}}{h^{2}}
\end{aligned}
$$

Optical diffusion equation (2.9) was solved using the finite difference method. The forms of the difference quotients were similar to those used to solve the advection-diffusion equation.

Most oxygen distribution problems involve non-linear tasks. Nonlinearities may result mainly from the assumed oxygen consumption model and/or from consideration of equations for the partial pressure of oxygen and the saturation of hemoglobin in the capillary subdomain. Due to these facts, in the current work, the task associated with the oxygen distribution was also solved with the use of the finite difference method for the steady-state problem in cylindrical coordinates with a grid based on a three-point stencil (radial direction). It was assumed that ( $h_{r}$ is the grid spacing in the radial direction)

$$
\begin{aligned}
& \frac{1}{r} \frac{d}{d r}\left(r \frac{d P_{t}}{d r}\right)_{i}=\frac{1}{r_{i} h_{r}}\left[\left(r \frac{d P_{t}}{d r}\right)_{i+\frac{1}{2}}-\left(r \frac{d P_{t}}{d r}\right)_{i-\frac{1}{2}}\right] \\
& \quad=\frac{1}{r_{i} h_{r}}\left[\left(r_{i}+\frac{1}{2} h_{r}\right) \frac{P_{t, i+1}-P_{t, i}}{h_{r}}-\left(r_{i}-\frac{1}{2} h_{r}\right) \frac{P_{t, i}-P_{t, i-1}}{h_{r}}\right]
\end{aligned}
$$

The capillary length was divided into $n_{z}$ elements $\left(m=0,1, \ldots, n_{z}\right)$. After determination of the partial pressure in tissue $P_{t}$ in the radial direction, for a given point $m$, saturation $S_{H b}$ is calculated in the point $m+1$ on the basis (Eq. (2.11))

$$
S_{H b, m+1}=-\frac{k h_{z}}{Q_{b} \kappa_{b}}\left(P_{b, m}-P_{t, m}\right)+S_{H b, m}
$$

\section{Results of computations}

The research aimed at analysing a thermal damage process in the 2D tissue and blood vessel domains during laser irradiation (Fig. 1 left). Dimensions of both subdomains were assumed equal to each other: $2 \mathrm{~cm} \times 0.2 \mathrm{~cm}$. The boundary and interior of the tissue subdomain were divided into 248 constant elements, whereas in the blood vessel subdomain $10^{5}$ nods were distinguished. In the oxygen distribution model, 100 nodes were distinguished in both the axial and radial directions.

Different values of optical parameters for both subdomains were considered. In the tissue subdomain $\Omega_{t}$, two values of the effective scattering coefficient related to the native $\mu_{s \text { nat }}^{\prime}$ and denatured $\mu_{s \text { den }}^{\prime}$ tissue were taken into account. In the blood vessel subdomain $\Omega_{v}$, different values of the absorption coefficient $\mu_{a}$, scattering coefficient $\mu_{s}$ and an anisotropy factor $g$ were used for oxygenated blood (saturation $S_{O 2}>90 \%$ ) and deoxygenated blood (saturation $S_{O 2}=0$ ) (Bosschaart et al., 2014) - Table 1. All possible combinations of these parameters were considered, which means that four simulations were performed (variant 1: native tissue-oxygenated blood, variant 2: native tissue-deoxygenated blood, variant 3: denaturated tissue-oxygenated blood, variant 4: denaturated tissue-deoxygenated blood). It should be pointed out that optical parameters correspond to near-IR irradiation on soft tissue (e.g. Nd:YAG laser of $1064 \mathrm{~nm}$, used for prostate coagulation). The remaining parameters used in simulations are presented in Tables 2 and 3. 
Table 1. Optical parameters of tissue and blood (Bosschaart et al., 2014; Glen et al., 1996)

\begin{tabular}{|l|c|c|c|c|}
\hline \multirow{2}{*}{ Parameter } & \multicolumn{2}{|c|}{ Tissue } & \multicolumn{2}{c|}{ Blood } \\
\cline { 2 - 5 } & native & denaturated & oxygenated & deoxygenated \\
\hline \hline Absorption coefficient $\mu_{a}\left[\mathrm{~m}^{-1}\right]$ & 40 & 40 & 450 & 200 \\
\hline Scattering coefficient $\mu_{s}\left[\mathrm{~m}^{-1}\right]$ & - & - & 47690 & 41520 \\
\hline Anisotropy factor $g\left[\mathrm{~m}^{-1}\right]$ & - & - & 0.9724 & 0.9732 \\
\hline Effective scattering coefficient $\mu_{s}^{\prime}\left[\mathrm{m}^{-1}\right]$ & 1000 & 4000 & - & - \\
\hline
\end{tabular}

Table 2. Parameters used in the simulations* (Glenn et al., 1996; Gonzalez-Suarez and Berjano, 2016; Jasiński, 2020; Paruch, 2020)

\begin{tabular}{|c|c|c|c|c|c|}
\hline Parameter & Value & Parameter & Value & Parameter & Value \\
\hline \hline$\lambda_{t}\left[\mathrm{Wm}^{-1} \mathrm{~K}^{-1}\right]$ & 0.609 & $T_{b}\left[{ }^{\circ} \mathrm{C}\right]$ & 37 & $\phi_{0}\left[\mathrm{~W} \mathrm{~cm}{ }^{-2}\right]$ & $1 \mathrm{e}+5$ \\
\hline$\lambda_{v}\left[\mathrm{Wm}^{-1} \mathrm{~K}^{-1}\right]$ & 0.52 & $A_{t}\left[\mathrm{~s}^{-1}\right]$ & $3.1 \mathrm{e}+98$ & $d[\mathrm{~mm}]$ & 2 \\
\hline$c_{t}\left[\mathrm{Jkg}^{-1} \mathrm{~K}^{-1}\right]$ & 4180 & $A_{v}\left[\mathrm{~s}^{-1}\right]$ & $7.6 \mathrm{e}+66$ & $t_{e x p}[\mathrm{~s}]$ & 30 \\
\hline$c_{v}\left[\mathrm{Jkg}^{-1} \mathrm{~K}^{-1}\right]$ & 3300 & $E_{t}\left[\mathrm{~J} \mathrm{~mole}^{-1}\right]$ & $6.27 \mathrm{e}+5$ & $\alpha_{0}\left[\mathrm{Wm}^{-2} \mathrm{~K}^{-1}\right]$ & 10 \\
\hline$\rho_{t}\left[\mathrm{~kg} \mathrm{~m}^{-3}\right]$ & 1000 & $E_{v}\left[\mathrm{~J} \mathrm{~mole}^{-1}\right]$ & $4.48 \mathrm{e}+5$ & $\alpha_{t v}\left[\mathrm{Wm}^{-2} \mathrm{~K}^{-1}\right]$ & 500 \\
\hline$\rho_{v}\left[\mathrm{~kg} \mathrm{~m}^{-3}\right]$ & 1030 & $R\left[\mathrm{~J} \mathrm{~mole}{ }^{-1} \mathrm{~K}^{-1}\right]$ & 8.314 & $T_{a m b}\left[{ }^{\circ} \mathrm{C}\right]$ & 20 \\
\hline$Q_{m e t t}\left[\mathrm{Wm}^{-3}\right]$ & 250 & $\mu[\mathrm{Pa} \mathrm{s}]$ & 0.0021 & $T_{p}\left[{ }^{\circ} \mathrm{C}\right]$ & 37 \\
\hline$Q_{m e t v}\left[\mathrm{Wm}^{-3}\right]$ & 250 & $u_{\text {in }}\left[\mathrm{cm} \mathrm{s}{ }^{-1}\right]$ & 1 & & \\
\hline \multicolumn{7}{|c|}{$w_{0}\left[\mathrm{~s}^{-1}\right]$} & 0.00125 & $p_{\text {out }}[\mathrm{mmHg}]$ & 125 & & \\
* Parameters not explained previously in the text: $u_{\text {in }}-$ inlet blood velocity, \\
$p_{\text {out }}-$ outlet blood pressure, $d-$ laser beam diameter, $t_{\text {exp }}-$ laser impulse duration, \\
$\alpha_{0}-$ convection coefficient at $\Gamma_{0}, \alpha_{t v}-$ convection coefficient at $\Gamma_{t v}$, \\
$T_{\text {amb }}$ - ambient temperature, $T_{p}-$ initial temperature of tissue and blood
\end{tabular}

Table 3. Parameters for the oxygen distribution model (McGuire and Secomb, 2001; Zhu et al., 2015)

\begin{tabular}{|c|c|c|c|}
\hline Parameter & Value & Parameter & Value \\
\hline \hline$R_{c}[\mathrm{~cm}]$ & 0.00025 & $k\left[\left(\mathrm{~cm}^{2} \mathrm{~s}^{-1}\right)\left(\mathrm{cm}_{\mathrm{O} 2}^{3} \mathrm{~cm}^{-3}(\mathrm{mmHg})^{-1}\right)\right]$ & $6.25 \mathrm{e}-9$ \\
\hline$R_{t}[\mathrm{~cm}]$ & 0.006 & $P_{b}[\mathrm{mmHg}]$ & 100 \\
\hline$L_{t}[\mathrm{~cm}]$ & 0.04 & $P_{50}[\mathrm{mmHg}]$ & 26 \\
\hline$K_{t}\left[\left(\mathrm{~cm}^{2} \mathrm{~s}^{-1}\right)\left(\mathrm{cm}_{O 2}^{3} \mathrm{~cm}^{-3}(\mathrm{mmHg})^{-1}\right)\right]$ & $9.4 \mathrm{e}-10$ & $n[-]$ & 2.7 \\
\hline$M_{0}\left[\mathrm{~cm}_{O 2}^{3} \mathrm{~cm}^{-3} \mathrm{~s}^{-1}\right]$ & 0.00667 & $\kappa_{b}\left[\mathrm{~cm}_{O 2}^{3} \mathrm{~cm}_{\text {blood }}^{-3}\right]$ & 0.2 \\
\hline$P_{0}[\mathrm{mmHg}]$ & 1 & & \\
\hline \multicolumn{2}{|r}{}
\end{tabular}

Figure 2 presents the distribution of the diffuse fluence rate $\phi_{d}$ resulting from steady-state optical diffusion equation (2.9) for all variants of computations. In the cases under consideration, an increase in $\phi_{d}$ occurred in line with an increase in $\mu_{s}^{\prime}$ in the tissue subdomain (i.e. for denaturated tissue) and in line with a decrease in $\mu_{a}$ and $\mu_{s}$ for blood (i.e. for deoxygenated blood). It is also worth noticing that for 2 and 4 variants of calculations (deoxygenated blood) the maximum $\phi_{d}$ values, which are achieved in the blood vessel subdomain, are clearly visible. For the oxygenated blood (variant 1 and 3 of the calculations), they are hardly visible or not noticeable at all.

Figures 3 and 4 show the temperature distribution for selected time steps. Comparison of these figures reveals that the energy delivered to the tissue-vessel domain under consideration is better discharged in the case of oxygenated blood (Fig. 3). This is, of course, influenced by higher temperature values achieved in variants 3 and 4 (Fig. 4). It is consistent with the results 

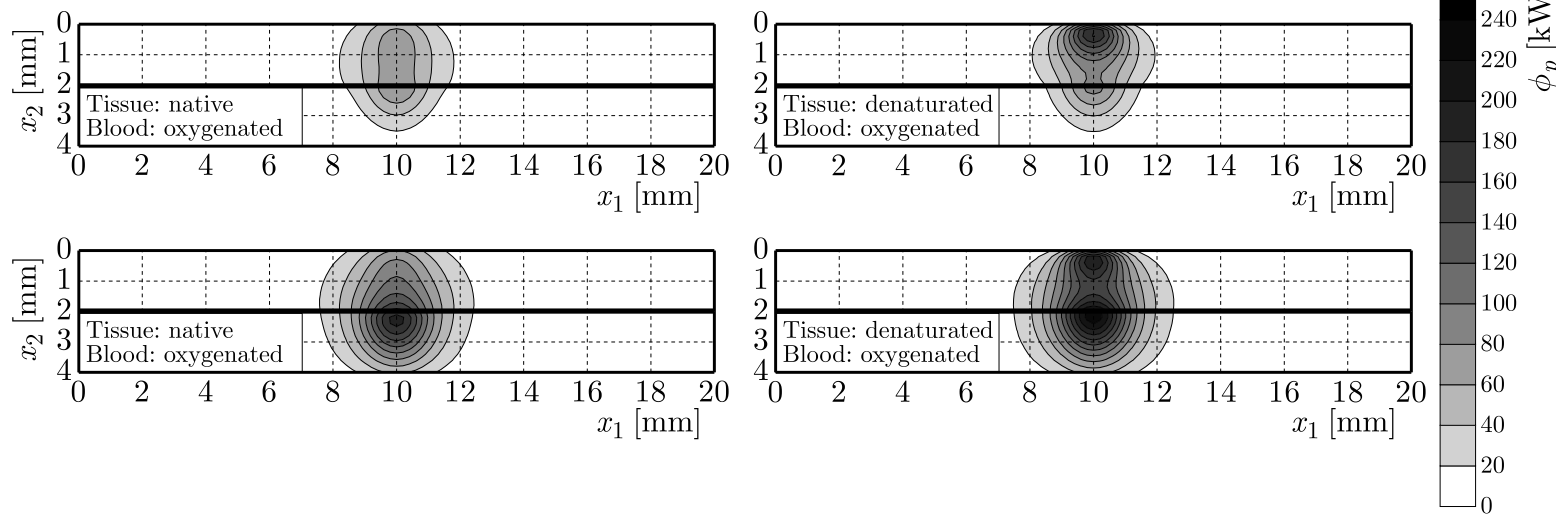

Fig. 2. Distribution of the diffuse fluence rate $\phi_{d}$ for all variants of computations
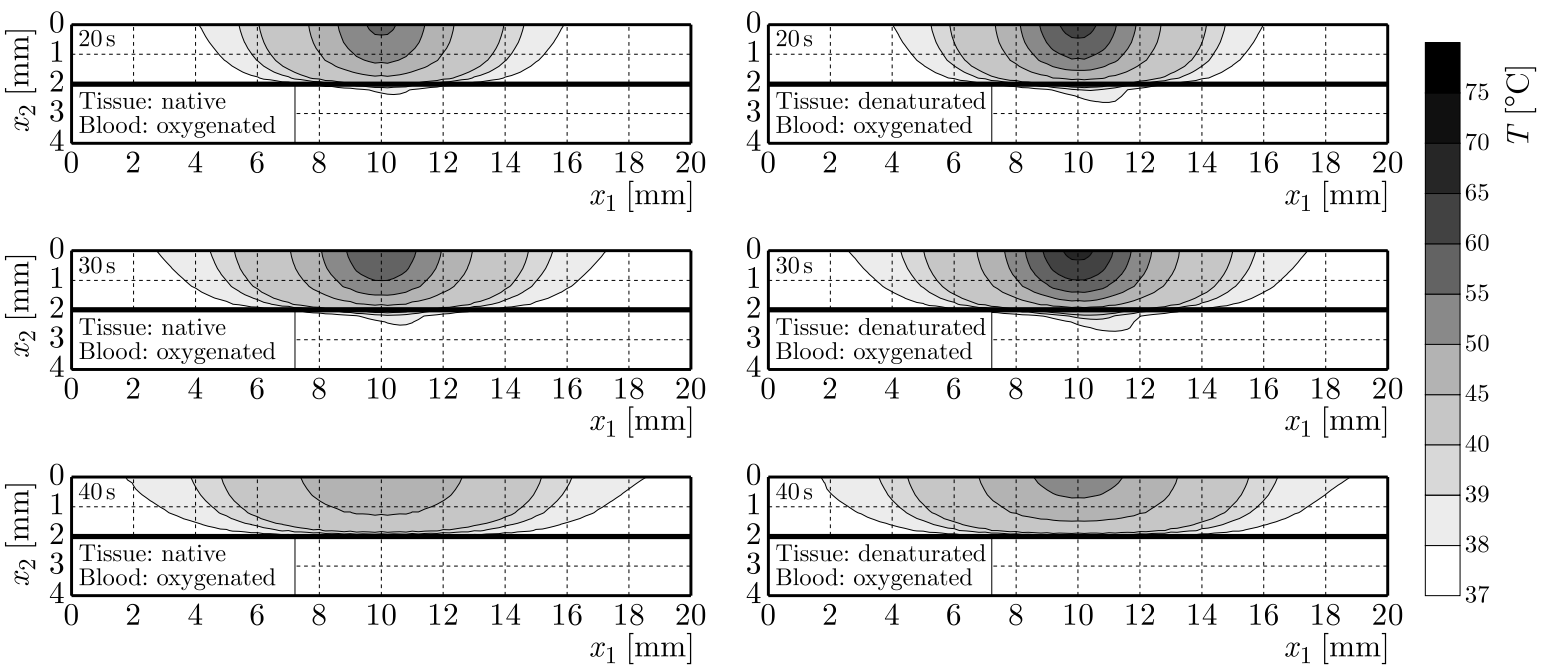

Fig. 3. Distribution of temperature for different time steps for variants 1 and 3 (oxygenated blood)
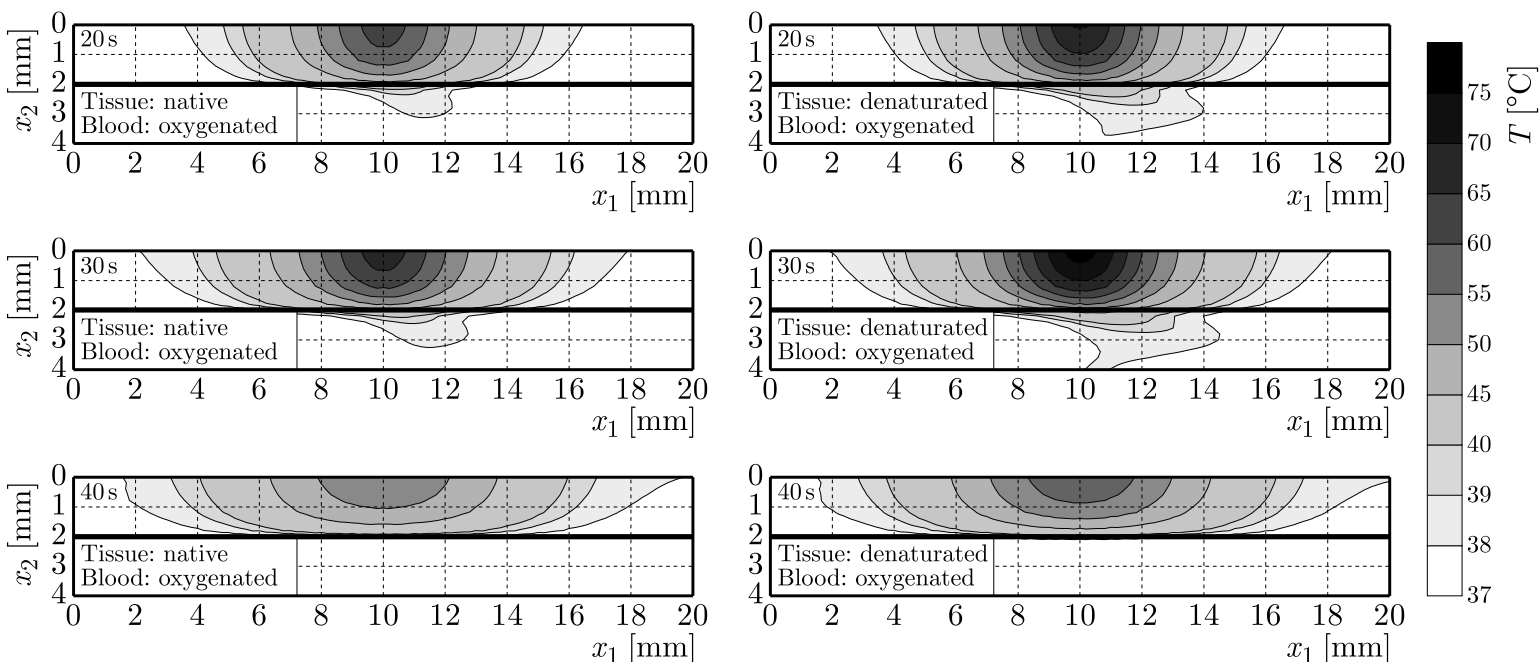

Fig. 4. Distribution of temperature for different time steps for variants 2 and 4 (deoxygenated blood) 
obtained for the optical diffusion equation. It should also be noted that once the laser pulse stops $\left(t_{\exp }=30 \mathrm{~s}\right)$, the temperatures in the blood vessel subdomain return to normothermia quite quickly.
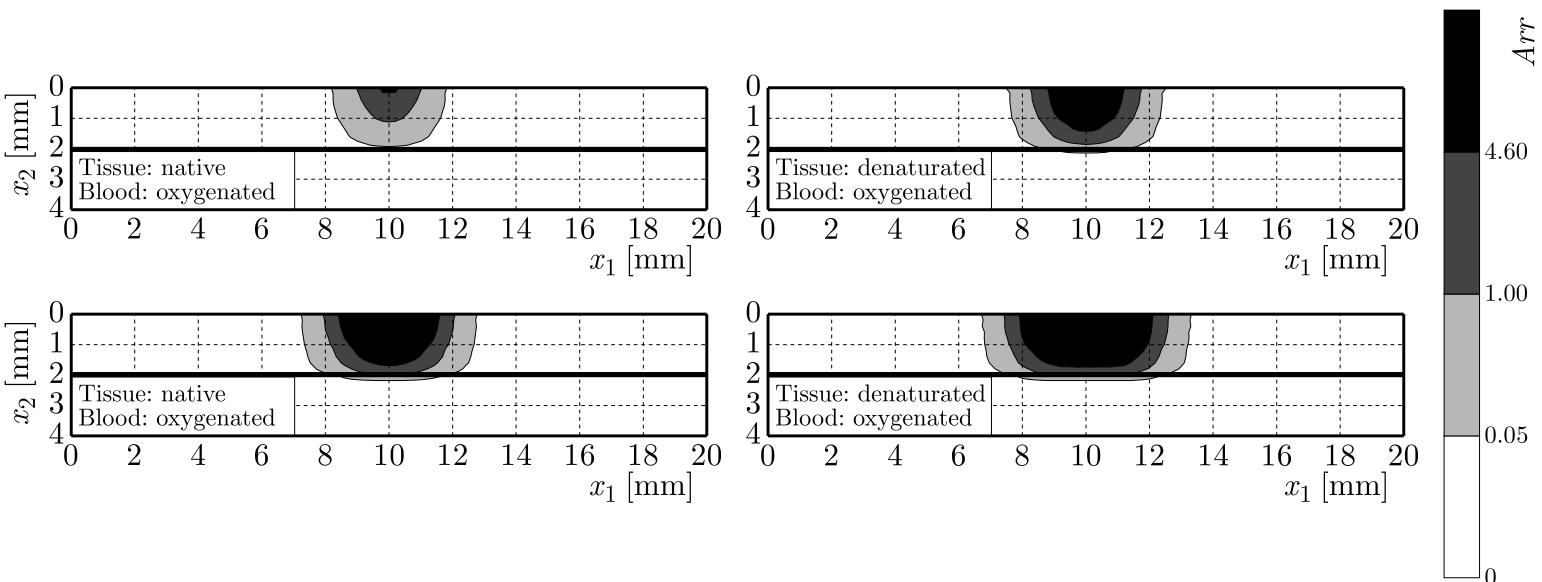

Fig. 5. Distribution of thermal damage for all variants of computations $(60 \mathrm{~s})$
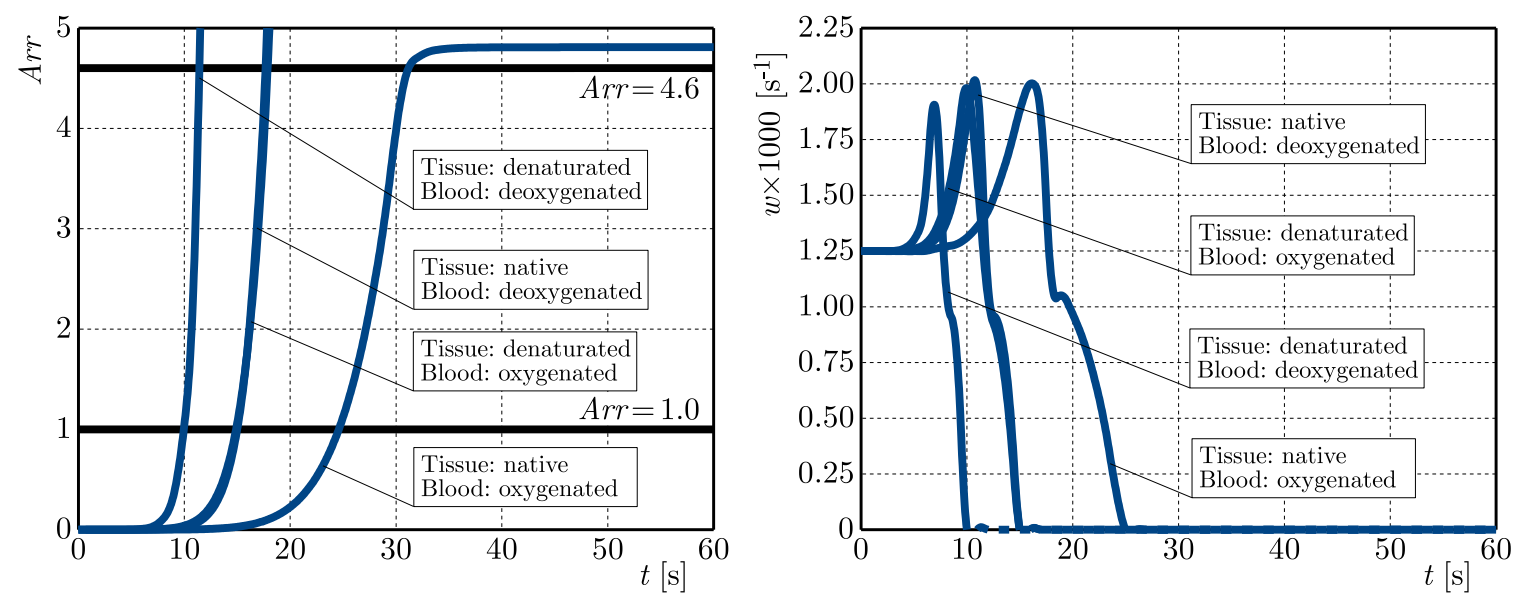

Fig. 6. The history of Arrhenius integral and perfusion coefficient at point $N_{1}$ $\left(x_{1}=0.01025, x_{2}=0.00025\right)$
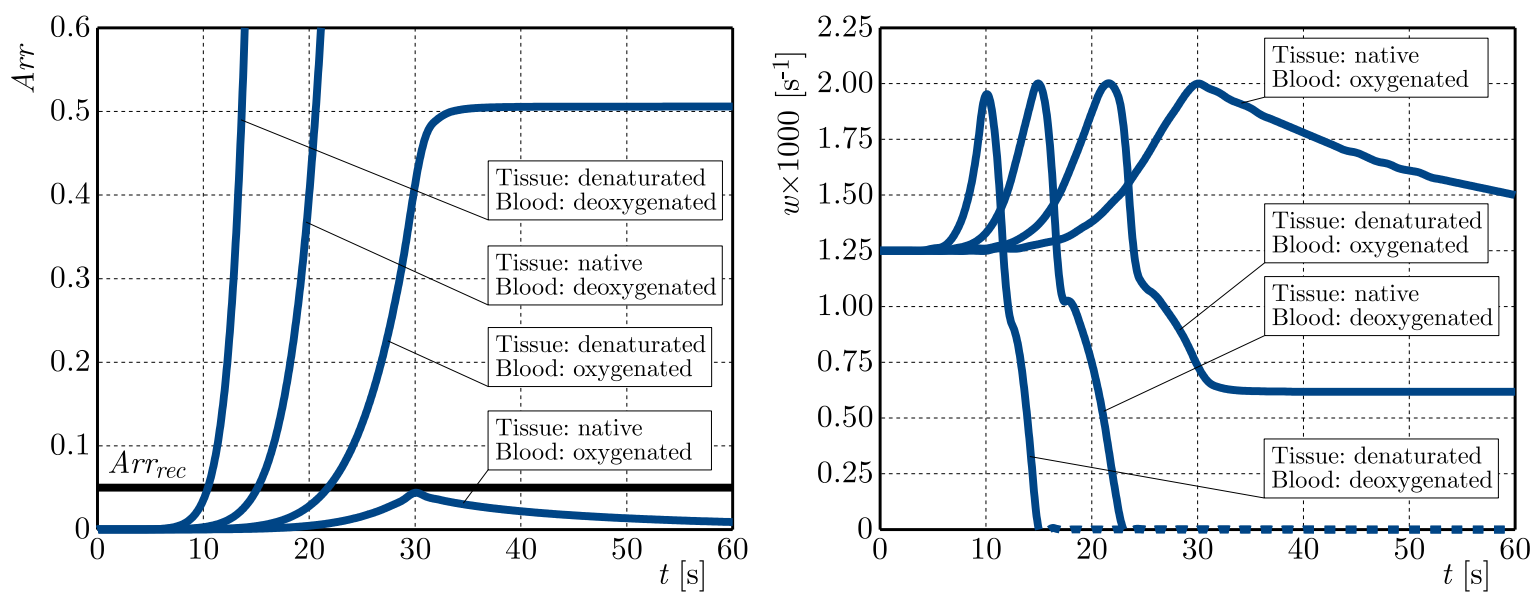

Fig. 7. The history of Arrhenius integral and perfusion coefficient at point $N_{2}$

$$
\left(x_{1}=0.01025, x_{2}=0.00175\right)
$$

Figures 5-7 are associated with thermal damage. In Fig. 5, the thermal damage distributions calculated on the basis of the Arrhenius injury integral with the TTIW algorithm for time $60 \mathrm{~s}$ 
are presented. The white zone in this figure refers to the injury integral below the so-called recovery threshold $\left(A r r_{r e c}=0.05\right)$, the values $0.05<A r r<1$ correspond to a partial damage area, and the remaining two darkest zones are associated with the two criteria of tissue necrosis: $\operatorname{Arr}\left(x_{1}, x_{2}\right)>1$ and $\operatorname{Arr}\left(x_{1}, x_{2}\right)>4.6$.

It should be explained that the recovery threshold is the parameter of the TTIW algorithm (thermal tissue injury withdrawal algorithm). If the degree of thermal damage is below this threshold, the value of damage could be reduced after the thermal impulse is stopped (Jasiński, 2018).

According to the results obtained for the temperature distribution, the largest damage area was obtained for variant 4 (denaturated tissue and deoxyganeted blood). In Figs. 6 and 7, the history of the thermal damage and damage-dependent perfusion coefficient (Eq. (2.2)) for all variants of computations in two points are presented. Both points are located close to the main optical axis in the tissue subdomain, point $N_{1}$ closer to the external surface of tissue, whereas $N_{2}$ closer to the tissue-blood vessel interface.
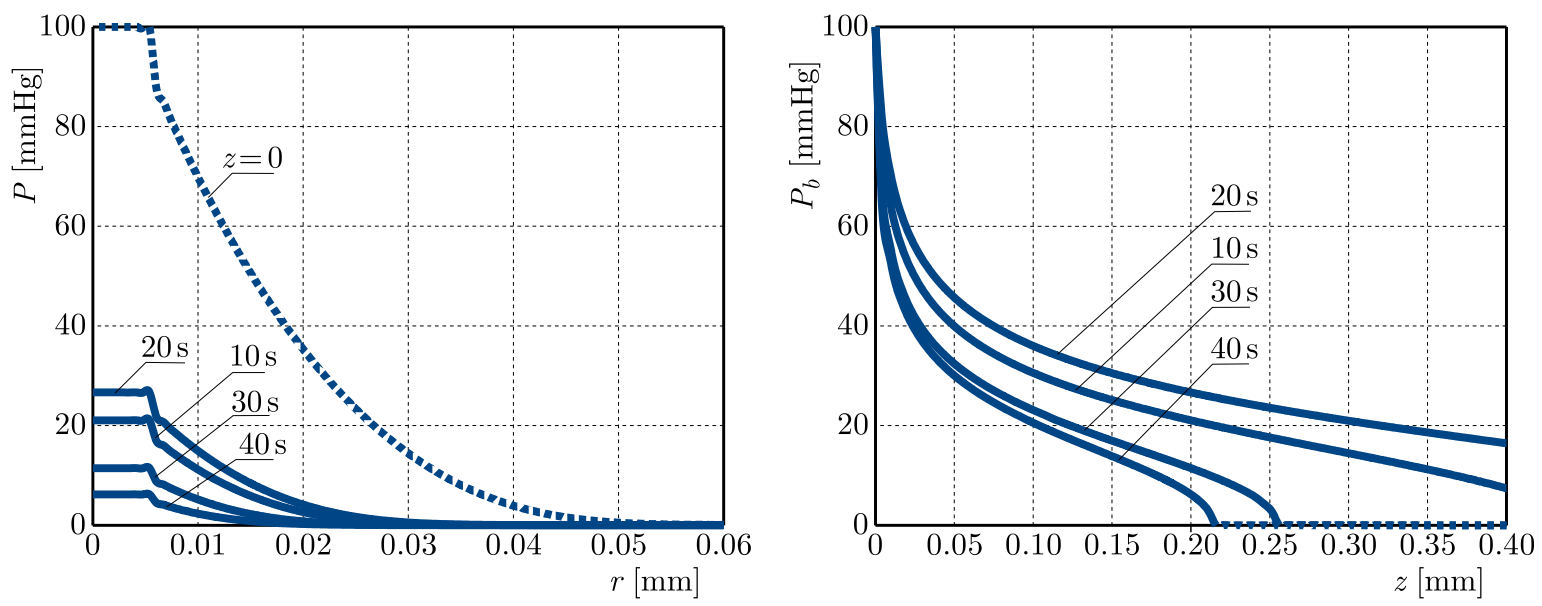

Fig. 8. Distribution of the partial pressure in the radial and axial directions at point $N_{2}$

(variant 3: denaturated tissue, oxygenated blood)

The last part of the analysis concerns the oxygen distribution, the results of which are presented in Fig. 8. As already mentioned, the value of blood velocity in the capillary $u_{b}$ was determined on the basis of the damage-dependent perfusion coefficient $w$ determined at point $N_{2}$ for variant 3 (Fig. 7). The value of this coefficient increases for 22 seconds, then starts to decrease, and in 34 seconds the value stabilizes at approximately $0.00062 \mathrm{~s}^{-1}(A r r=0.5014)$. In the radial direction, the distributions at $z=L_{t} / 2$ are presented. Due to the very small difference between the distributions for $0 \mathrm{~s}$ and $10 \mathrm{~s}$, the former was omitted (Fig. 7). The distribution for 20 seconds is above that for 10 seconds. For 30 and 40 seconds they are below that curve, what is in accordance with the results obtained for the perfusion coefficient. The figure for the axial direction shows that for 10 seconds, that is, $u_{b}$ calculated for the value close to the initial perfusion coefficient $w_{0}$ (and thus close to the normothermia state), the partial pressure is $P_{b}>0$ in the entire capillary length. However, for time steps 30 and 40 seconds, the partial pressure drops to zero at the end of the capillary, which means that the area of the tissue adjacent to it became hypoxic. Therefore, it can be concluded that thermal damage causes a decrease in the oxygen supply to the tissue.

It should be noted that in this analysis a constant value of $P_{b}$ was assumed on the capillary inlet for each time step while elevated temperature could cause damage also at higher levels of vasculature, i.e. in arterioles and venules. As a consequence, it may cause a change in the partial pressure of oxygen at the capillary inlet. In the current work, constant values of $P_{50}$ (the 
half-maximal haemoglobin saturation) and $n$ (Hill coefficient) were also assumed, although it is known that a change in temperature can affect their values (so-called Bohr effect).

\section{Final remarks}

In summary, the main findings of the paper are as follows:

- Differences in the diffuse fluence rate distribution for different combinations of optical parameters of (native and denatured) tissue and (oxygenated and deoxygenated) blood are clearly visible. The highest values of the diffuse fluence rate were obtained for denatured tissue and deoxygenated blood (variant 4). These values affect the internal heat source function related to laser deposition $Q_{\text {las }}$, and thus the temperature reached in the domain under consideration as well as the area of tissue damage.

- The largest damaged area was obtained for denatured tissue and deoxygenated blood (variant 4) and was limited to the tissue subdomain only. It means that in the case of blood vessel presence, a damage process takes place differently than in the case of homogeneous tissue (cf. Jasiński, 2018).

- For oxygenated blood (variant 1 and 3), an increase in temperature in the blood vessel subdomain is very small, which indicates a better heat discharge from the area of elevated temperature.

- Thermal damage to the tissue affects the distribution of oxygen in the tissue. If the value of the Arrhenius integral exceeds the necrosis threshold, the partial pressure in the capillary drops to zero at half of its length, which means hypoxia in the area of adjacent tissue.

The presented model obviously has some limitations. They are primarily related to the assumption of some parameters as constants. For example, it is known that the parameters of the oxyhemoglobin dissociation curve $\left(P_{50}, n\right)$ change with increasing temperature, leading to its shift to the right (Jasiński, 2020b). The effect of laser irradiation on blood velocity in a large blood vessel was also not considered. In the model related to the oxygen distribution, a constant partial pressure $P_{b}$ at the capillary inlet was assumed, although it is obvious that thermal injury damages the vasculature at higher levels, thus reducing the partial pressure of oxygen at lower levels of the vasculature.

Analysis of heat exchange phenomena in tissue containing blood vessels is usually quite complex, resulting from a number of issues that must be taken into account. A variety of methods and approaches are discussed in the literature. In particular, formulation of an appropriate mathematical model and issues related to numerical implementation are the areas of scientific and practical interest.

The performed simulations show that the oxygen content of the blood influences the rate of discharge of laser pulse energy from its area of operation. Such issues are also analysed. A more accurate understanding of the phenomena that occur in tissue during thermal exposure certainly requires taking into account chemical reactions taking place inside, where models of the oxygen distribution can certainly help.

\section{Acknowledgements}

The research is funded from the projects of Silesian University of Technology, Faculty of Mechanical Engineering.

\section{References}

1. Abraham J.P., Sparrow E.M., 2007, A thermal-ablation bioheat model including liquid-to-vapor phase change, pressure- and necrosis-dependent perfusion, and moisture-dependent properties, International Journal of Heat and Mass Transfer, 50, 2537-2544 
2. Akula S.C., Maniyeri R., 2020, Numerical simulation of bioheat transfer: a comparative study on hyperbolic and parabolic heat conduction, Journal of the Brazilian Society of Mechanical Sciences and Engineering, 42, 62

3. Bessonov N., Sequeira A., Simakov S., Vassilevskit Yu., Volpert V., 2016, Methods of blood flow modelling, Mathematical Modelling of Natural Phenomena, 11, 1-25

4. Bosschaart N., Edelman G.J., Aalders M.C.G., van Leeuwen T.G., Faber D.J., 2014, A literature review and novel theoretical approach on the optical properties of whole blood, Lasers in Medical Science, 29, 453-479

5. Brebia C.A., Dominguez J., 1992, Boundary Elements, an Introductory Course, 2nd ed. Computational Mechanics Publications, McGraw-Hill Book Company, London

6. Caro C.G., Pedley T.J., Schroter R.C., Seed W.A., 2012, The Mechanics of the Circulation, 2nd ed., Cambridge University Press

7. Dombrovsky L.A., 2012, The use of transport approximation and diffusion-based models in radiative transfer calculations, Computational Thermal Sciences, 4, 297-315

8. Friebel M., Roggan A., Müller G., Meinke M., 2006, Determination of optical properties of human blood in the spectral range 250 to $1100 \mathrm{~nm}$ using Monte Carlo simulations with hematocrit-dependent effective scattering phase functions, Journal of Biomedical Optics, 11, 034021

9. Glenn T.N., Rastegar S., Jacques S.L., 1996, Finite element analysis of temperature controlled coagulation in laser irradiated tissue, IEEE Transactions on Biomedical Engineering, 43, $79-86$

10. Gonzalez-Suarez A., Berjano E., 2016, Comparative analysis of different methods of modeling the thermal effect of circulating blood flow during RF cardiac ablation, IEEE Transactions on Biomedical Engineering, 63, 250-259

11. Haghighi A.R., Asl M.S., Kiyasatfar M., 2015, Mathematical modeling of unsteady blood flow through elastic tapered artery with overlapping stenosis, Journal of the Brazilian Society of Mechanical Sciences and Engineering, 37, 571-578

12. Hassanpour S., Saboonchi A., 2016, Modeling of heat transfer in a vascular tissue-like medium during an interstitial hyperthermia process, Journal of Thermal Biology, 62, 150-158

13. Jacques S.L., Pogue B.W., 2008, Tutorial on diffuse light transport, Journal of Biomedical Optics, 13, 1-19

14. JAsiński M., 2018, Numerical analysis of soft tissue damage process caused by laser action, AIP Conference Proceedings, 1922, 1-10

15. JAsińsKi M., 2020a, Modeling of injury process of biological tissue containing blood vessel caused by laser impulse, AIP Conference Proceedings, 2239, 20019

16. JAsińsKi M., 2020b, Numerical analysis of the temperature impact to the oxygen distribution in the biological tissue, Journal of Applied Mathematics and Computational Mechanics, 19, 3, 17-28

17. Korczak A., Jasiński M., 2019, Modelling of biological tissue damage process with application of interval arithmetic, Journal of Theoretical and Applied Mechanics, 57, 249-261

18. McGuire B.J., Secomb T.W., 2001, A theoretical model for oxygen transport in skeletal muscle under conditions of high oxygen demand, Journal of Applied Physiology, 91, 2255-2265

19. Majchrzak E., Turchan L., Jasiński M., 2019, Identification of laser intensity assuring the destruction of target region of biological tissue using the gradient method and generalized dual-phase lag equation, Iranian Journal of Science and Technology-Transactions of Mechanical Engineering, 43, 539-548

20. Müller L.O., PArés C., Toro E., 2013, Well-balanced high-order numerical schemes for one-dimensional blood flow in vessels with varying mechanical properties, Journal of Computational Physics, 242, 53-85 
21. PARuch M., 2017, Identification of the cancer ablation parameters during RF hyperthermia using gradient, evolutionary and hybrid algorithms, International Journal of Numerical Methods for Heat and Fluid Flow, 27, 674-697

22. PARUCh M., 2020, Mathematical modeling of breast tumor destruction using fast heating during radiofrequency ablation, Materials, 13, 136

23. Paul A., PAul A., 2018, Computational study of photo-thermal ablation of large blood vessel embedded tumor using localized injection of gold nanoshells, Journal of Thermal Biology, 78, 329-342

24. Whiteley J.P., Gavaghan D.J., Hahn C.E.W., 2002, Mathematical modelling of oxygen transport to tissue, Journal of Mathematical Biology, 44, 503-522

25. Zhu T.C., Liu B., Penjweini R., 2015, Study of tissue oxygen supply rate in a macroscopic photodynamic therapy singlet oxygen model, Journal of Biomedical Optics, 20, 038001

Manuscript received October 5, 2021; accepted for print January 11, 2022 